\title{
Using Remote Sensing Techniques in Environmental Management
}

\author{
Mihai Valentin HERBEI ${ }^{1 *}$, Roxana HERBEI ${ }^{2}$, Laura SMULEAC ${ }^{3}$, Tudor SALAGEAN ${ }^{4}$ \\ ${ }^{1}$ Cartography and GIS, Banat University of Agricultural Sciences and Veterinary Medicine, "Regele \\ Mihai I al României", from Timisoara, Calea Aradului 119, 300645, Timisoara, Romania \\ ${ }^{2}$ Cartography and Surveying, University of Petrosani, Romania \\ ${ }^{3}$ Sustainable Development, Banat University of Agricultural Sciences and Veterinary Medicine "Regele \\ Mihai I al României" from Timisoara, Romania \\ ${ }^{4}$ University of Agricultural Sciences and Veterinary Medicine Cluj-Napoca, Romania \\ * corresponding author: mihai_herbei@yahoo.com
}

Bulletin UASVM series Agriculture 73(2)/2016

Print ISSN 1843-5246; Electronic ISSN 1843-5386

DOI 10.15835/buasvmcn-agr: 12441

\begin{abstract}
The Geographical Information Systems technology is used in many fields where the spatial information is very important and relevant, that means in all fields that use a system for saving, analyzing and representing the data which are processed. The aim of this paper is using modern technology for monitoring the environment. Geographical Information System together with remote sensing have a very important role in decision process regarding the environment. Integration of remote sensing images in a Geographical Information System which enables complex spatial analysis is a useful and modern solution for environmental management and decisionmaking process. Satellite images contain various information that can support environmental monitoring, images that can be analyzed and interpreted in various ways by using the Geographical Information System tools.
\end{abstract}

Keywords: NDMI, NDVI, NDWI, vegetation index.

\section{INTRODUCTION}

Some studies for identifying the changes have shown that modifications between data related to vegetation properties are well identified when images are enhanced using vegetation indices before making the difference between images (Fung 1990; Coppin and Bauer 1996; Radeloff et al. 2000, Rogan et al. 2002). These methods allow the identification of subtle changes related to density, composition and growth conditions of vegetation (Horablaga et al. 20123) depending on the purpose and the spatial scale of the project (Rogan et al. 2003). Another area where image analysis is used quite a lot is an attempt to assess plant health and to discover their potential diseases. Other authors (Pena-Barragan et al. 2012) aim to identify weeds in a cultivated area considering the crop rows. Other articles are trying to find a way to identify those lands where the amount of pesticide used is too high, reaching the level where it is detrimental to both crops and people (Maxwell 2011). This category also contains the articles that use different vegetation indices to determine the chlorophyll content of the crop and, in this way, to discover whether they are healthy or not (Haboudane et al. 2002, Daughtry et al. 2000). There are other studies that aim to identify the degree of water evapotranspiration from plants. One such study was conducted for a region from Morocco to better prepare residents for irrigation (Simonneaux et al. 2007). Besides these elements which were studied by means of remote sensing and aimed to obtain a better production per hectare and healthier plants, and studies have been made to estimate the production of a specific crop. Some of the people who were dedicated 


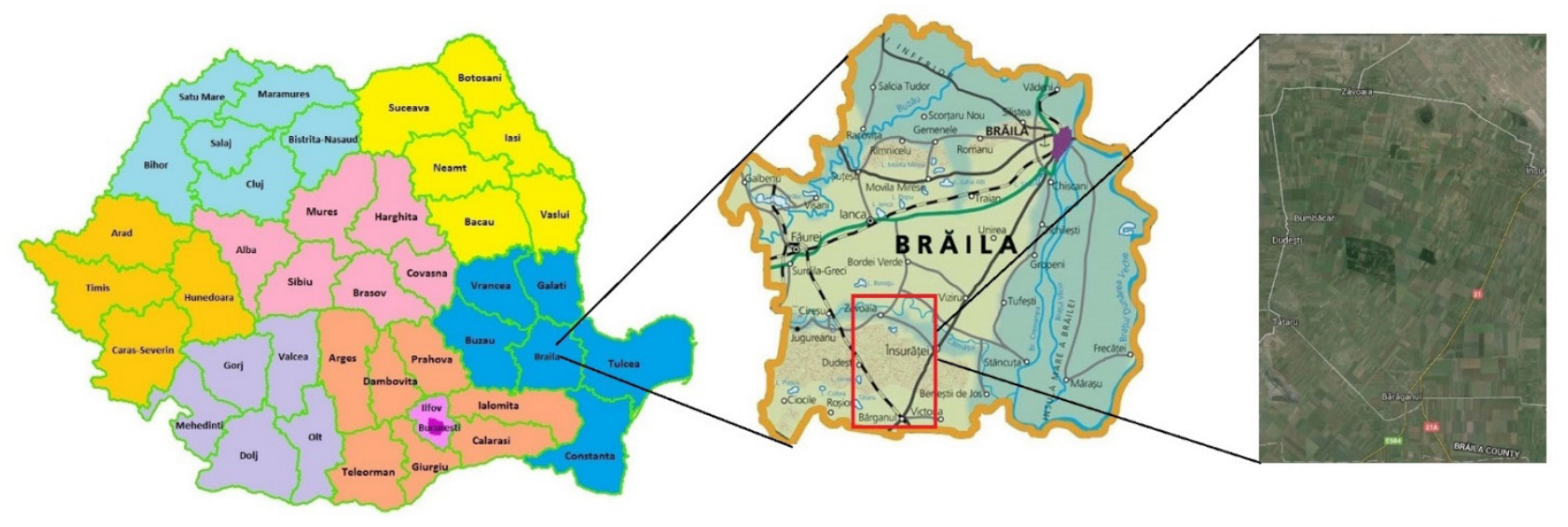

Fig. 1. Geographical location of territory

to these types of studies have tried to develop indices to estimate the productivity of crops without considering their type (Zhao et al. 2013). Others have tried to focus on determining the productivity of a single type of crop, for example, corn crops and soybeans (Johnson 2014), wheat (Kowalik et al. 2014) and including production of grape vine crops (Serrano et al. 2012, Govederica et al. 2015). Other studies are based not only on trying to predict the yield per hectare but also trying to determine how plants will grow or how the amount collected will differ within the same parcel. This can only be achieved using satellite images or aerial photographs of very high spatial resolution (Yang et al. 2013).

\section{MATERIALS AND METHODS}

Based on satellite images, there were calculate a series of normalized differential indexes resulting from some operations with the spectral bands, meaning they are obtained based on multispectral images (with several spectral bands). Through specific operations, it is aimed to amplify spectral signatures in the band where one particular object has the highest reflectance and diminishing signature of the certain object in the band where it has the lowest reflectance. Following these transformations, resulting are normalized indexes represented in gray scale images, where pixels have new numerical values. The data obtained is no longer byte (0-255, for 8-bit images), but floating point type, ranging between -1 and 1 . Using remote sensing for agricultural land management has a very high potential because of fast information of high quality that can be obtained based on satellite images on vegetation cover.
Territory of the analyzed area, lies at the junction of major geographical units, respectively Romanian Plain and Dobrogea Plateau, in the southern part of Braila county, located close to the contact area of two counties: Braila and Ialomita, Plain Bărăganului. The area under study is intersected by the parallel of $45^{\circ}$ north latitude (Viziru Tufesti) and meridian $28^{\circ}$ east longitude (east of Braila and Mărașu) and lies between $47^{\circ} 45^{\prime} 02^{\prime \prime}, 47^{\circ} 51^{\prime} 52^{\prime \prime}, 47^{\circ} 51^{\prime} 38^{\prime \prime}$ and $47^{\circ} 44^{\prime} 48^{\prime \prime}$ north latitude and $23^{\circ} 28^{\prime} 51^{\prime \prime}, 23^{\circ} 28^{\prime} 39^{\prime \prime}, 23^{\circ} 12^{\prime} 11^{\prime \prime}$ and $23^{\circ} 12^{\prime} 25^{\prime \prime}$ east longitude.

Nomalized Difference Index represent the result of mathematical operations aimed to highlight the characteristics of the environment (Begov Ungur 2015, Begov Ungur 2013, Govedarica $M$ et al. 2012) using two spectral bands. The most important normalized difference indices are present futher and the method of building the maps containing these indices. (Herbei et al. 2015, Herbei et al. 2015)

Using software ArcGIS (Herbei 2015; Herbei et al. 2015) , these indices have been calculated and the maps have been done for the studied area, using satellite images. Then the mathematics of the bands for each indicator was performed from ArcGIS Spatial Analyst - Map Algebra -Raster Calculator.

\section{RESULTS AND DISCUSSION Normalized difference vegetation index NDVI}

NDVI values vary depending on the absorption of radiation by the chlorophyll in the red spectral area and its reflectance in the near infrared spectral area. These values are between -1 and +1 , 
Tab. 1. Indices used and their formulas

\begin{tabular}{|c|c|}
\hline INDICES & Formula \\
\hline $\begin{array}{l}\text { Normalized difference } \\
\text { vegetation index } \\
\text { NDVI }\end{array}$ & NDVI $=(N I R-R) /(N I R+R)$ \\
\hline $\begin{array}{c}\text { Normalized difference } \\
\text { water index } \\
\text { NDWI }\end{array}$ & $\mathrm{NDWI}=(\mathrm{NIR}-\mathrm{G}) /(\mathrm{NIR}+\mathrm{G}$ \\
\hline $\begin{array}{l}\text { Normalized difference } \\
\text { moisture index } \\
\text { NDMI }\end{array}$ & NDMI $=(N I R-I R) /(N I R+I R)$ \\
\hline $\begin{array}{c}\text { Normalized difference } \\
\text { built-up index } \\
\text { NDBI }\end{array}$ & NDBI $=(I R-N I R) /(I R+N I R)$ \\
\hline $\begin{array}{c}\text { (Modified) Soil -adjusted } \\
\text { vegetation index } \\
\text { SAVI } \\
\text { MSAVI }\end{array}$ & $\begin{array}{l}\qquad S A V I=\frac{N I R-R E D}{(N I R+R E D+L)} *(1+L) \\
\text { where } L=1-\frac{2 * S *(N I R-R E D) *(N I R-S * R E D)}{N I R+R E D} \\
\text { where } s \text { is the slope of the soil line from a plot of red versus near infrared brightness } \\
\text { values } \\
\qquad M S A V I 2=\frac{\left(2 * N I R+1-\sqrt{(2 * N I R+1)^{2}}-8 *(N I R-R E D)\right.}{2}\end{array}$ \\
\hline
\end{tabular}

expressing the consistency of green vegetation. Values close to +1 (light tones) represent high consistency of the vegetation and they are specific to dense hardwood forests. Values close to -1 (dark tones) is the land lacking vegetation with soil or rock. The value 0 (midtones) is associated with land meadows. It is useful in mapping areas with vegetation, vegetation typology, the health of vegetation, the use of land, etc.

\section{Normalized difference water index NDWI}

It is useful in mapping water bodies, visualizing the turbidity differences and vegetation content of water, alluvial soils or in the case of differentiation of water content in vegetation. It uses green spectral bands (electromagnetic radiation penetrates water) and near infrared (increases spectral response of moisture in soils, rocks and plants, and water begins to absorb radiation in the surface layers). Drak tones (values close to -1) express the water surface. Light tones (values close to +1), dry land. Midtones (values close to 0), lands with intermediate moisture content.

\section{Normalized difference moisture index NDMI}

Interpretation: light tones (excess moisture), dark tones (low humidity). Represents the different moisture content in the landscape and in particular elements of soil, rocks and vegetation (good indicator of the droughts occurrence). Values bigger than 0.1 symbolized by light tones express high humidity. Low values (close to -1) symbolized by the dark tones express low humidity. It is useful in mapping water potential.

\section{Normalized difference built-up index NDBI}

Light tones (land with crops and constructions), dark tones (land occupied by forests). NDBI values vary depending on the spectral signatures of middle infrared band (high reflectance of moisture in soil, vegetation, rocks, including construction materials) and near infrared band (high reflectance of chlorophyll). Lighter tones (positive values) symbolize the land covered by buildings. Dark tones (negative values) symbolize other landscape elements (forests, farmland, etc.). It is useful in automatic mapping of human settlements, as well as some elements of the land (dams, canals, railroads, roads, dams, etc.).

(Modified) Soil -adjusted vegetation index

\section{SAVI and MSAVI}

There is currently great interest in quantitative characterization of the spatial and temporal patterns of vegetation representing data from the distance for the study of earth system science and 

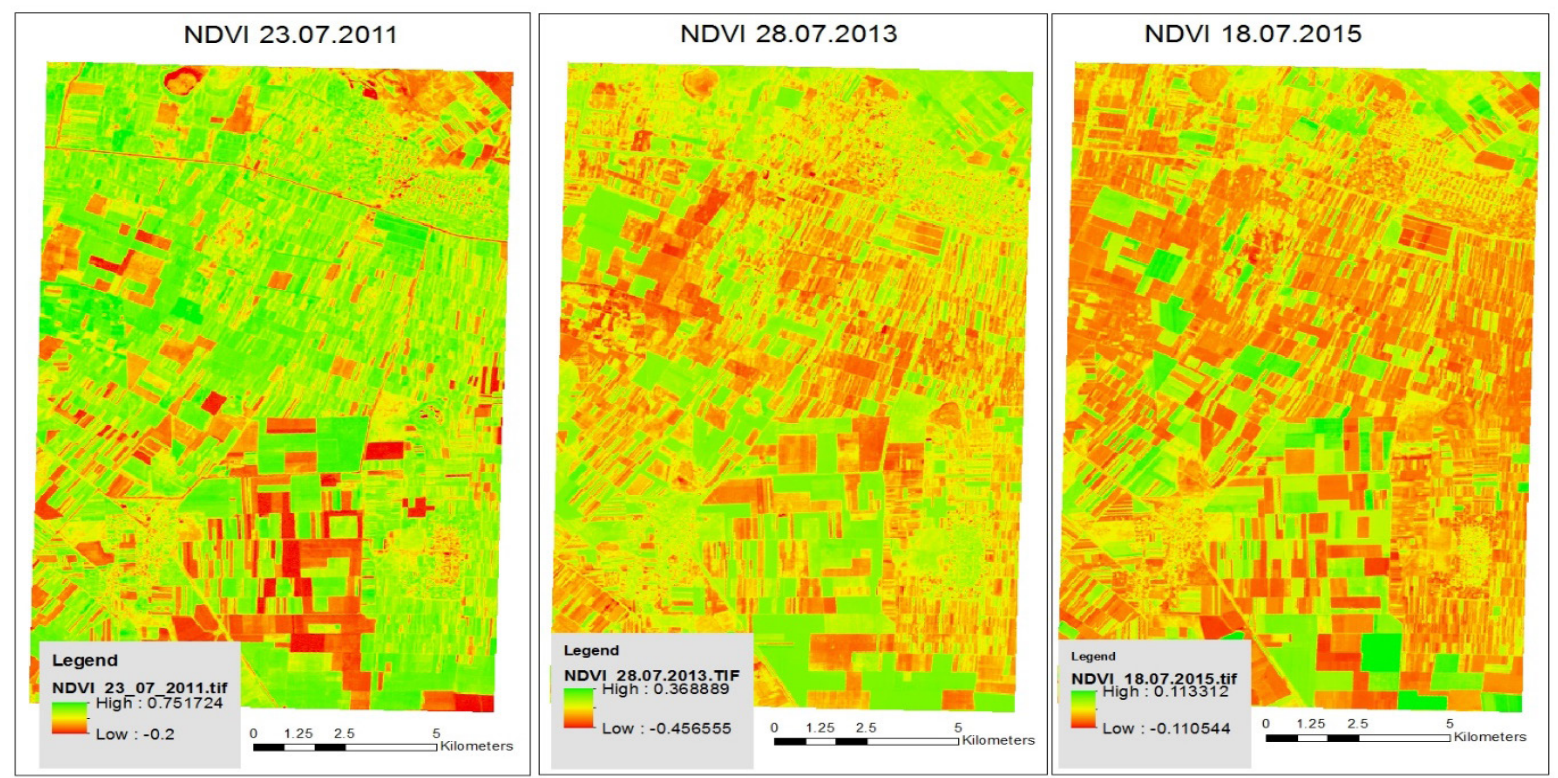

Fig. 2. Evolution of indices NDVI in the period 2011-2013-2015
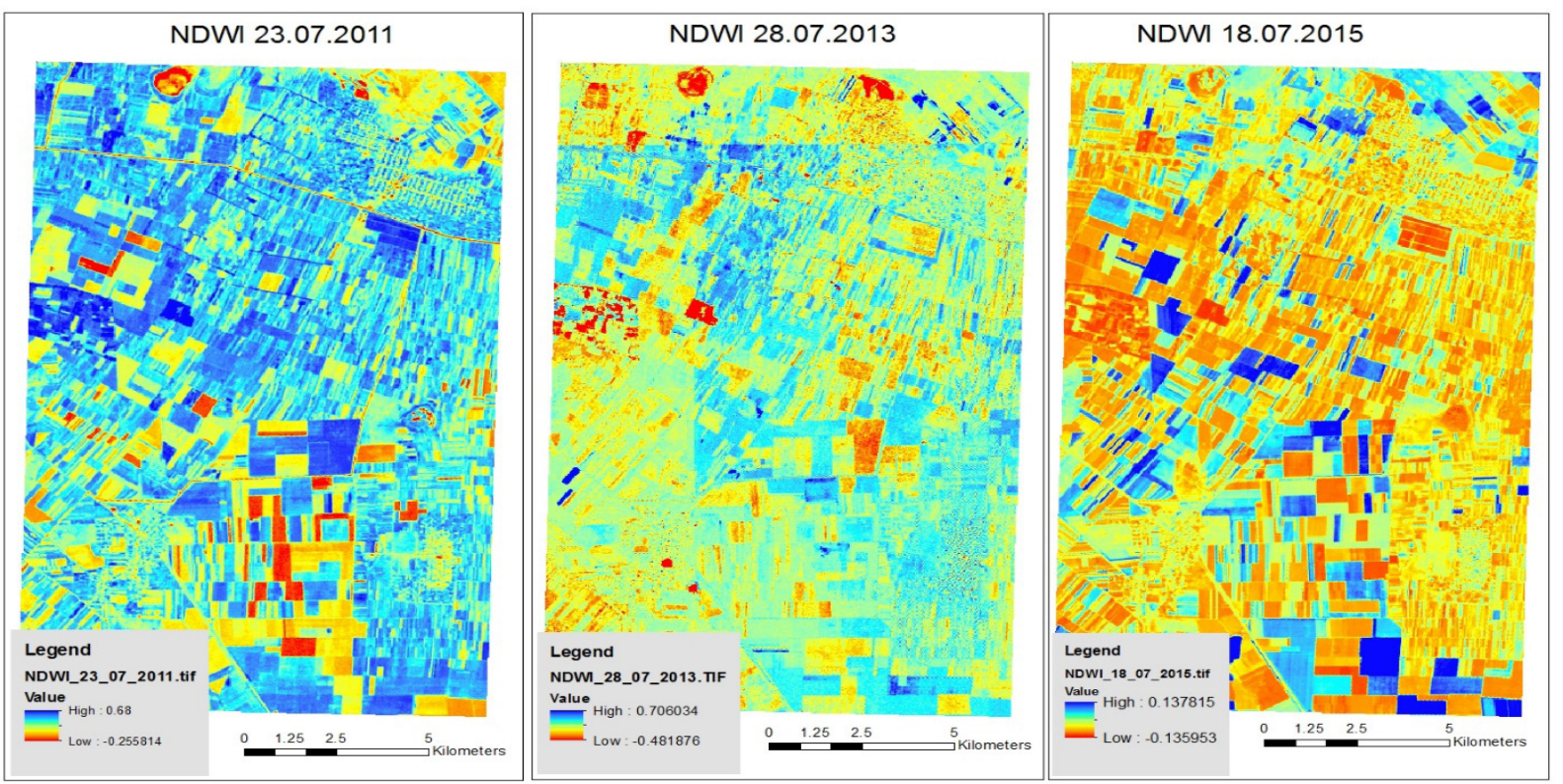

Fig. 3. Evolution of indices NDWI in the period 2011-2013-2015

global change. Spectral models and indices are developed to improve the sensitivity of vegetation by accounting effects of the atmosphere and soil. In areas where vegetation topsoil is low (meaning, <40\%) and the soil surface is exposed, the reflection of light in red and near-infrared spectrum can influence vegetation index values.

This is particularly problematic when comparisons are made on different soil types, which may reflect different amounts of light in red wavelengths and near infrared (ie, soils with different brightness values). Adjusted vegetation index according to the soil was developed as a modification of the normalized difference vegetation index (NDVI) to correct the influence of soil brightness when vegetation topsoil is low.

SAVI is structured similar to NDVI, but by adding a "correction factor of soil light" MSAVI 

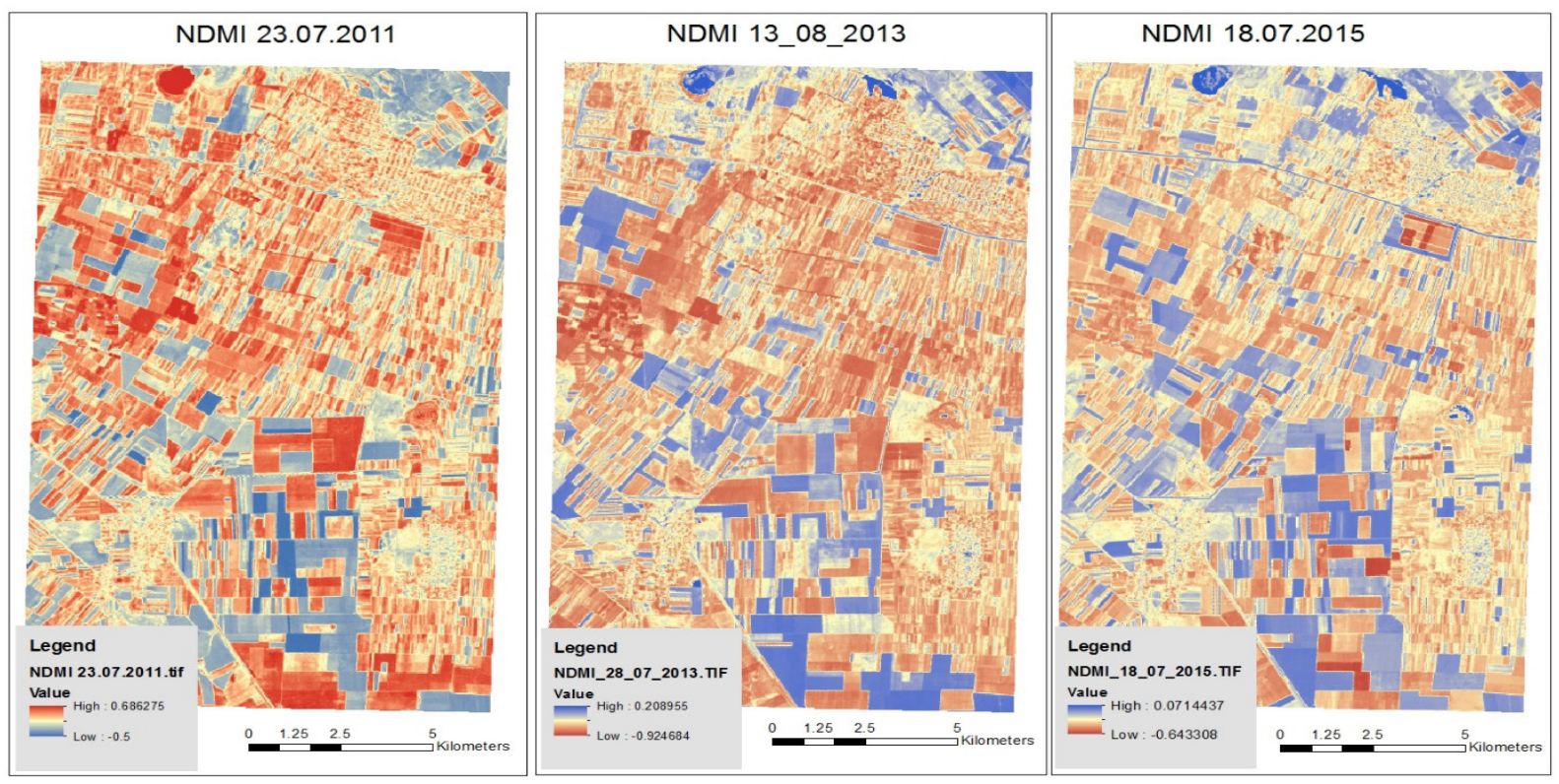

Fig. 4. Evolution of indices NDMI in the period 2011-2013-2015
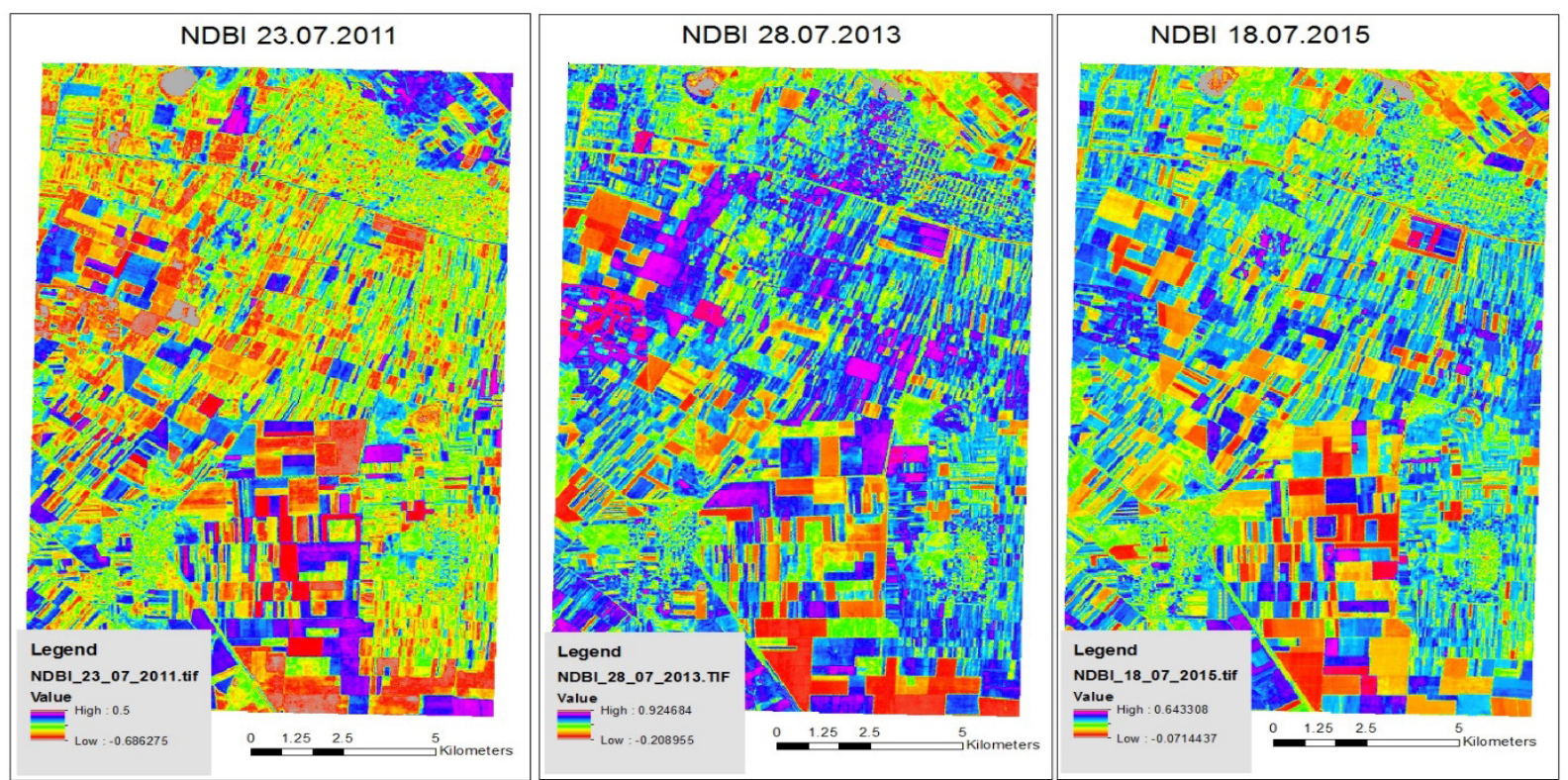

Fig. 5. Evolution of indices NDBI in the period 2011-2013-2015

requires one band red and one band near infrared to be calculated. Adjusted vegetation index accoding to the soil (SAVI) was developed to minimize influences of the soil on the spectral canopy by incorporating an adjustment factor of the soil $\mathrm{L}$ in the denominator of the equation for the normalized difference vegetation index (NDVI). For the optimum adjustment effect of the soil, the factor L should vary inversely compared to the amount of vegetation present. SAVI amended (MSAVI), which replaces the constant $\mathrm{L}$ in the equation SAVI to a variable function $\mathrm{L}$. $\mathrm{L}$ function can be derived by induction or by using of the NDVI product and weighted difference (WDVI). MSAVI aims to increase the dynamic range of the signal vegetation while further minimizes background influences of soil, resulting in greater sensitivity of vegetation. A formula was obtained, called MSAVI2, which eliminates the need to find 

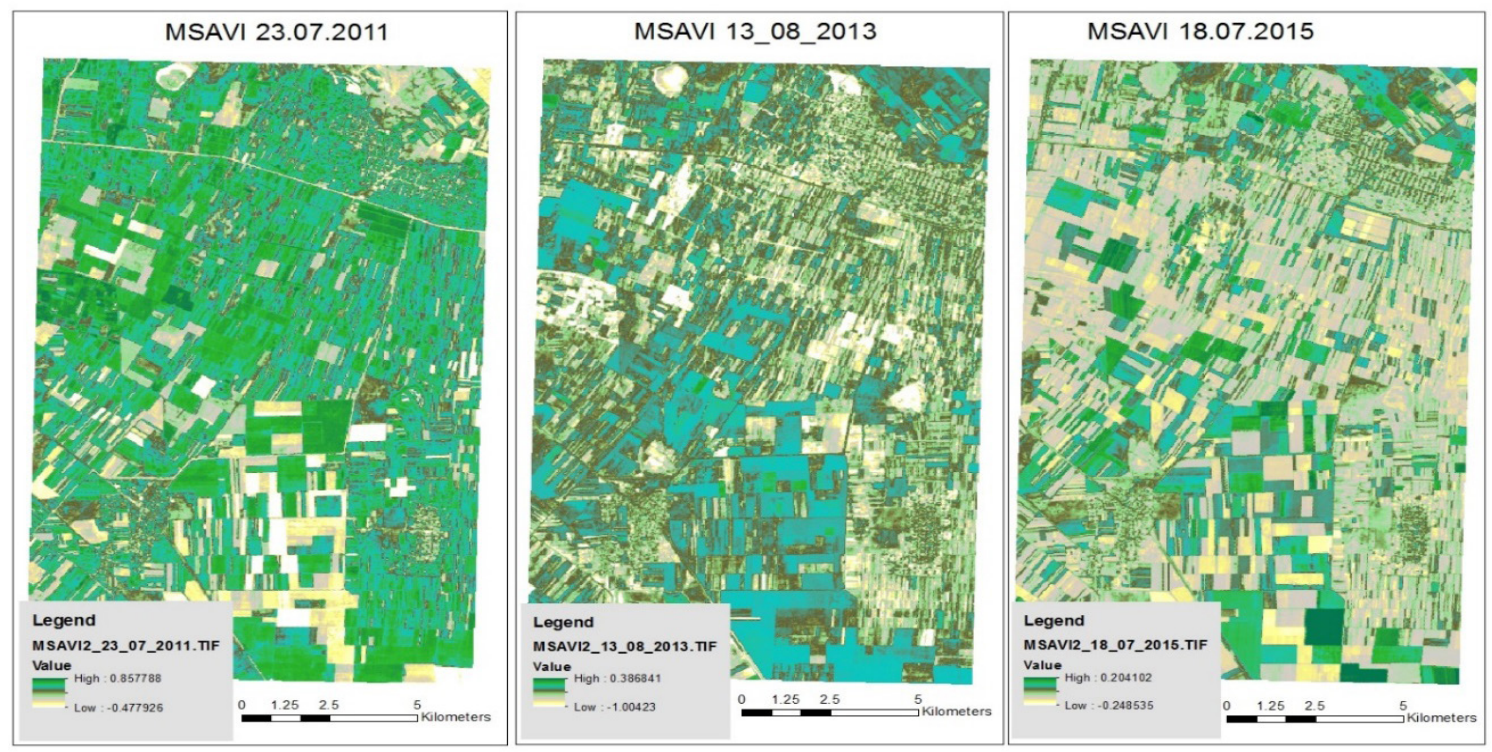

Fig. 6. Evolution of indices MSAVI in the period 2011-2013-2015

Tab. 2. Table of correlations for vegetation indices 2011

\begin{tabular}{ccccccc}
\hline 2011 & NDVI & NDWI & NDMI & NDBR & NDBI & MSAVI \\
\hline NDVI & 1 & & & & & \\
\hline NDWI & $\mathbf{0 . 9 7 9 9 5 1}$ & 1 & & & & \\
\hline NDMI & 0.820021 & 0.803778 & 1 & & & \\
\hline NDBR & 0.849482 & 0.855646 & 0.981791 & 1 & & \\
\hline NDBI & -0.82002 & -0.80378 & -1 & $\mathbf{0 . 9 8 1 7 9}$ & 1 & \\
\hline MSAVI & $\mathbf{0 . 9 9 7 0 7 9}$ & $\mathbf{0 . 9 6 8 6 6 3}$ & 0.797264 & 0.819657 & -0.79726 & 1 \\
\hline
\end{tabular}

Tab. 3. Table of correlations for vegetation indices 2013

\begin{tabular}{ccccccc}
\hline 2013 & NDVI & NDWI & NDMI & NDBR & NDBI & MSAVI \\
\hline NDVI & 1 & & & & & \\
\hline NDWI & -0.59622 & 1 & & & & \\
\hline NDMI & $\mathbf{0 . 9 0 5 6 9 6}$ & -0.75318 & 1 & & & \\
\hline NDBR & 0.532862 & -0.85125 & 0.793834 & 1 & & \\
\hline NDBI & $\mathbf{- 0 . 9 0 5 7}$ & 0.75318 & -1 & -0.79383 & 1 & \\
\hline MSAVI & 0.793236 & -0.20801 & 0.646054 & 0.153679 & -0.64605 & 1 \\
\hline
\end{tabular}

the ground line of a characteristic space or even specify a brightness correction factor of the soil.

MSAVI calculation formula itself is the same formula as SAVI, and MSAVI2 is generally the version used when people refer to MSAVI. MSAVI was used in a number of studies where it was often correlated with terrain data for vegetation cover, biomass and/or leaf area index, and as an entry layer for classes cover, land mapping or vegetation.

\section{CONCLUSION}

Vegetation indices calculated based on the satellite data Landsat 8 have been analysed also from the correlation point of view. Thus in 
Tab. 4. Table of correlations for vegetation indices 2015

\begin{tabular}{ccccccc}
\hline 2015 & NDVI & NDWI & NDMI & NDBR & NDBI & MSAVI \\
\hline NDVI & 1 & & & & & \\
\hline NDWI & $\mathbf{0 . 9 8 8 5 1 8}$ & 1 & & & & \\
\hline NDMI & 0.840409 & 0.782901 & 1 & & & \\
\hline NDBR & 0.238965 & 0.271647 & 0.023607 & 1 & & \\
\hline NDBI & -0.84041 & -0.7829 & -1 & -0.02361 & 1 & \\
\hline MSAVI & $\mathbf{0 . 9 9 6 9 3 4}$ & $\mathbf{0 . 9 7 7 6 0 2}$ & 0.87423 & 0.198835 & -0.87423 & 1 \\
\hline
\end{tabular}

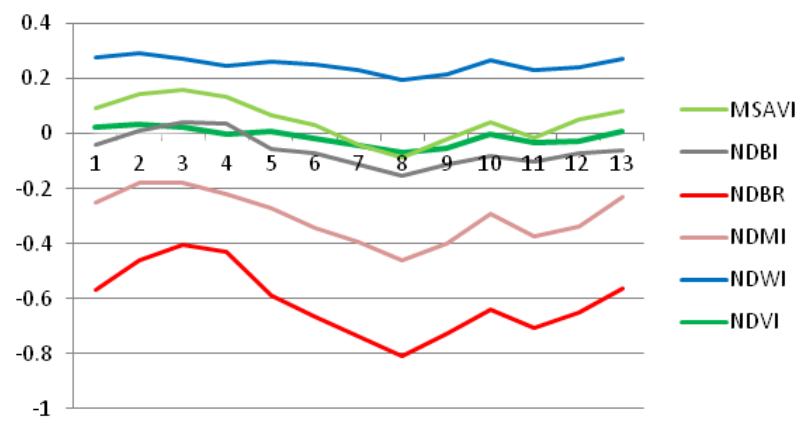

Fig. 7. The evolution of vegetation indices in 2011

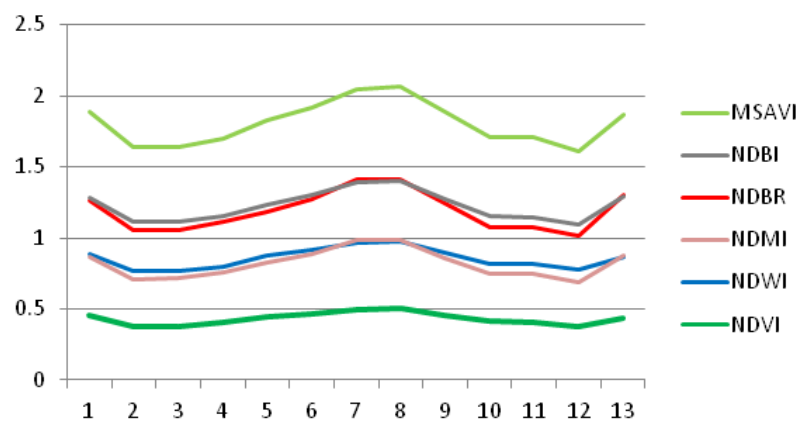

Fig. 8. The evolution of vegetation indices in 2013

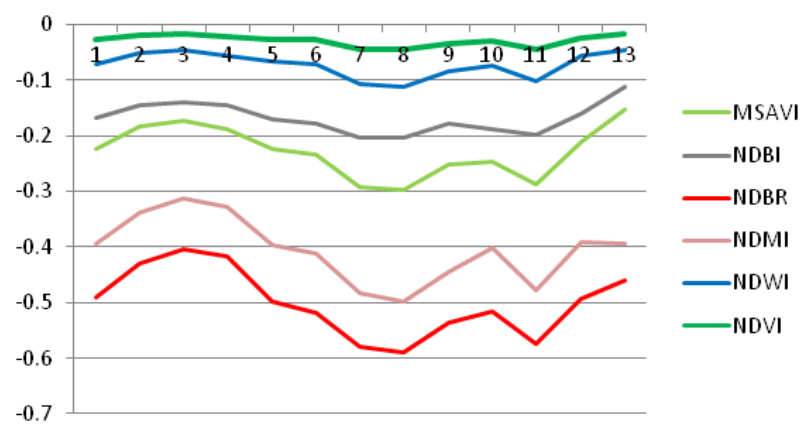

Fig. 9. The evolution of vegetation indices in 2015 conclusion, the best correlations are between indices NDVI and NDWI, respectively MSAVI, between indices NDWI and MSAVI, berween indices NDMI and NDBR and NDBR and NDBI. Results are presented in Tabs 2, 3 and 4 . In the graphs from figures 7,8,9 we have presented the distribution of vegetation indices calculated abd analysed for the study area, in the period 2011, 2013 and 2015.

\section{REFERENCES}

1. Begov Ungur A (2015). Researches Regarding the Decanting Pond 'Valea Salistei', in View of Areal Rehabilitation and Returning It to the Agricultural Circuit, Journal of Environmental Protection and Ecology, 16(3):1061- 1069.

2. Begov Ungur A (2013). Topographical Survey and Proposals Concerning the Rehabilitation of the Tailings Dump in Gura Rosiei in View of Returning It to the Agricultural Circuit, Journal of Environmental Protection and Ecology, 14(3):1041- 1050.

3. Coppin PR, Bauer ME (1996). Digital change detection in forest ecosystems with remote sensing imagery. Remote Sensing Reviews, 13(3-4):207-234.

4. Daughtry CST, Walthall CL, Kim MS, Brown de Colstoun E, McMurtrey E (2000). Estimating Corn Leaf Chlorophyll Concentration from Leaf and Canopy Reflectance. Remote Sensing of Environment, Elsevier Science Inc., 74:229239.

5. Fung, T (1990). An assessment of TM imagery for landcover change detection.Transactions on Geoscience and Remote Sensing, 28:681-684.

6. Govedarica M, Petrovački D, Sladić D, Radulović A, Jovanović D, Pajić V, Vrtunski M and Ristić A (2012). Environmental data in Serbian spatial data infrastructure - Geoportal of ecology. J of Environmental Protection and Ecology 13(3A):1990-1997.

7. Govedarica M, Ristic A, Jovanovic D, Herbei M, Sala F (2015). Object Oriented Image Analysis in Remote Sensing 
of Forest and Vineyard Areas. Bulletin of University of Agricultural Sciences and Veterinary Medicine ClujNapoca. Horticulture. Vol. 72(2):362-370.

8. Haboudane D, Miller JR, Tremblay N, Zarco-Tejada PJ, Dextranze (2002). Integrated narrow-band vegetation indices for prediction of crop chlorophyll content for application to precision agriculture. Remote Sensing of Environment (Elsevier Science Inc., 18:416-426.

9. Herbei MV, Herbei RC, Radulov I (2015). Topology of spatial data, SGEM2015 Conference Proceedings, Book2, 2:1175-1182.

10. Herbei MV, Herbei RC, Popescu CA, Bertici R(2015). Domogled - Valea Cernei National Park monitoring using satellite technology. Ecoterra 12(3):73-78 p.

11. Herbei M, Sala F, Boldea M (2015). Relation of normalized difference vegetation index with some spectral bands of satellite images. AIP 1648:670003-1-67003-4.

12. Herbei M (2015). GIS si Modelare cartografica. Universitas, Petroasni, 151-160.

13. Horablaga A, Tabara V, Popescu G, Horablaga N (2013). Results obtained at Oenothera biennis L. Regarding the content and production of oil and determination of linoleic acid, oleic acid in organic production, Research Journal of Agricultural Sciences, vol. 45(3):86-93.

14. Johnson DM (2014). An assessment of pre- and withinseason remotely sensed variables for forecasting corn and soybean yelds in United States. Remote Sensing of Environment, Elsevier Science Inc. 141:116-128.

15. KowalikW, Dabrowska-Zielinska K, Meroni M, Razka TU, de Wit A (2014). Yield estimation using SPOT-VEGETATION products: A case study of wheat in European countries." International Journal of Applied Earth Observation and Geoinformation, Elsevier Science Inc.

16. Pena-Barragan J.M., Kelly M., de-Castro A.I., LopezGranados F. (2012). Object-based approach for crop row characterization in UAV images for site-specific weed management. Proceedings of GEOBIA. Rio de Janeiro.
17. Radeloff VC, Mladenoff DJ, Boyce MS (2000). Effects of interacting disturbances on landscape patterns: Budworm defoliation and salvage logging. Ecological Applications, 233-247.

18. Rogan, J., Franklin, J., Roberts, D. A. (2002). A comparison of methods for monitoring multitemporal vegetation change using Thematic Mapper imagery. Remote Sensing of Environment, 80(1):143-156.

19. Rogan, J., Miller, J., Stow, D., Franklin, J., Levien, L., Fischer, C. (2003). Land cover change mapping in California using classification trees with Landsat TM and ancillary data. Photogrammetric Engineering and Remote Sensing, 69(7):793-804.

20. Maxwell Susan K (2011). Generating land cover boundaries from remotely sensed data using objectbased image analysis: overview and epidemiological application." Spat Spatiotemporal Epidemiol, National Institutes of Health 1 (4):231-237 .

21. Serrano L, Gonzalez-Flor C, Grochs G (2012). Assessment of grape yeld and composition using the reflectance based Water Index in Mediterranean rainfed vineyards." Remote Sensing of Environment, Elsevier Science Inc. 118:249258.

22. Simonneaux V, Duchemin B, Helson D, Er-Raki S, Oliosos A, Chehboun AG (2007). The use of high-resolution image time series for crop classification and evapotranspiration estimate over an irrigated area in central Morocco." International Journal of Remote Sensing.

23. Yang C, Everitt JH, Du Q Luo B, Chanussot J (2013). Using High-Resolution Airborne and Satellite Imagery to Assess Crop Growth and Yield Variability for Precision Agriculture." Proceedingd of the IEEE. IEEE.

24. Zhao Y, Sining C, Shuanghe S (2013). Assimilating remote sensing information with crop model using Ensemble Kalman Filter for improving LAI monitoring and yield estimation." Ecological Modelling, Elsevier Science Inc. 270:30-42. 